\title{
Registrars' and senior registrars' perceptions of their audit activities
}

\author{
Jenny Firth-Cozens, David Storer
}

\begin{abstract}
Objectives - To ascertain the level and quality of audit activity among junior doctors, their attitudes to audit, and their views on its educational value.
\end{abstract}

Design - Postal questionnaire survey in April 1991.

Setting - Yorkshire region.

Subjects - All 610 registrars and senior registrars recorded as employed in the region.

Main measures - Grade, current specialty, details of last audit participated in and its educational usefulness, and attitude to audit.

Results - 255(41.8\%) completed questionnaires were returned, 148 from registrars and 101 from senior registrars; grade was not indicated in six. 27 respondents were in general medicine, 26 in general surgery, 30 in anaesthetics, and 36 in psychiatry; other specialties had fewer than 20 respondents. About a fifth (54) of respondents, most in psychiatry $(19 / 36,53 \%)$, had not participated in audit. Among the 201 who had participated, the audit topics covered most components of care (access to services $(47,23 \%)$, communication (51, $25 \%)$, and appropriateness $(158,79 \%)$ and effectiveness $(157,78 \%)$ of treatment); only $84(41 \%)$ audits set standards, and in only half of them had the doctors been involved in doing so. Doctors responsible for gathering data and those responsible for collating and reporting data found their experience significantly less useful than those who were not. $172(86 \%)$ respondents considered that audit had helped patient care. Suggested improvements to the educational value of audit were mostly for better methods but included requests for less "witch hunting," better feedback, more training, more time, and more participation by consultants.

Conclusions - The educational value of audit to junior doctors could be improved by better audit methods, guidance, and feedback.

(Quality in Health Care 1992;1:161-164)

Postoraduate Medical Education, University of Leeds, Yorkshire Health, Harrogate David Storer, associate postgraduate dean

Correspondence to: Dr Firth-Cozens

Accepted for publication 6 April 1992
Committee for the Secretaries of State Health and Wales have recommended that medical schools, postgraduate deans, and health authorities ensure that an understanding of the principles of medical audit should become an essential part of undergraduate and postgraduate education. ${ }^{1}$ The Standing Committee on Postgraduate Medical Education (SCOPME) has also detailed the educational strengths of audit and warned against the use of audit as a disciplinary measure. It has recommended identification of training needs in medical audit as a high priority. ${ }^{2}$

In addition to these requirements, audit undoubtedly has a unique educational role in encouraging doctors to consider outcomes in terms of the more positive aspects of quality of care they might expect. Moreover, its experiential nature gives it the possibility of questioning individual practice and teaching about the uncertainty inherent in many aspects of care in a way that lectures can never capture.

The introduction of audit alongside sweeping management change has somewhat blurred this important educational feature so that for some audit has developed connotations of a management tool to monitor doctors rather than to educate, and this could lead to negative attitudes in junior doctors. Moreover, much of these doctors' time is already spent in repetitive and routine tasks which they do not perceive as having educational or clinical value, ${ }^{3}$ and it is undesirable that audit should come to be seen similarly. For this reason the ways in which audit is introduced to junior staff seems particularly important.

As an associate postgraduate dean, one of us (DS) has in the past two years participated in many interview committees for the appointment of registrars and senior registrars. It is now common for applicants to be questioned about their experience of and attitudes towards audit. The variation in the nature of the answers has been striking and was part of the motivation for carrying out this study. Some aspiring registrars are already skilled, enthusiastic, and experienced in audit methods and are able to educate their interviewers and to give examples of advanced audit projects which they have carried out. At the opposite extreme some applicants have no experience of audit and have difficulty in even attempting a basic definition of medical audit. Almost all applicants express a wish to be offered the opportunity of training in audit techniques.

This study aimed at investigating the audit experiences of registrars and senior registrars 
to capture the present position and quality of audit activity, both overall and in the various specialties, and at ascertaining their views on how the audit process could be improved for them educationally and their attitudes to audit.

\section{Subjects and methods}

In April 1991 all 610 registrars and senior registrars on record as employed by districts within the Yorkshire region were sent a postal audit questionnaire with a covering letter from $\mathrm{JF}-\mathrm{C}$ and DS; an envelope addressed to JF-C was included for return of the questionnaire.

The questionnaire comprised two parts. The first part asked the doctors for their grade, the number of months at that grade, the specialty of their current post, and specific details of the last audit in which they had taken part, which included questions on the particular component of care that the audit addressed (access to services, communication, appropriateness of treatment, and effectiveness of treatment). The questionnaire also asked whether standards were set or not, whether the respondents were part of the team which set the standards, whether they were responsible for collecting data and for collating and reporting it, whether they could see how the audit might improve the service to patients (yes or no), and how useful in educational terms participation in that audit had been (on a 1-5 scale ranging from "not useful at all" to "extremely useful"). In addition, respondents were asked to complete an open ended question: "What would have made the whole process more useful to you?"

The second part of the questionnaire contained a 38 item survey of views on audit. This consisted of 38 statements followed by a scale from 1 ("strongly disagree") to 5 ("strongly agree"). The statements had been chosen from those made by consultants in a series of workshops on audit run by JF-C. They contained equal numbers of positive and negative statements. Negative statements were recoded so that a higher score represented a more positive attitude. Examples of these statements were: "audit will be very time consuming;" "audit will help links with general practice;" "my time and the service's money could be much better spent on direct patient care;" and "audit will improve patient care."

Analysis - Data were analysed with a CompuAdd PC with SPSS-PC statistical software. Statistical analysis was by frequencies, means $t$ tests for independent samples, and Pearson correlations.

\section{Results}

Of the 610 questionnaires sent out, a total of 255 were returned, a response rate of $41.8 \%$; $148(58 \%)$ were from registrars and $101(40 \%)$ from senior registrars (six subjects did not indicate their grade). In terms of the specialties represented $27(11 \%)$ were in general medicine, $26(10 \%)$ in general surgery, $30(12 \%)$ in anaesthetics, $36(14 \%)$ in psychiatry, $17(7 \%)$ in radiology, $13(5 \%)$ in orthopaedic surgery, $12(5 \%)$ in pathology and cardiology, and $11(4 \%)$ in paediatrics and obstetrics and gynaecology. Other specialties were represented by very small numbers of respondents $(<11)$.

The respondents who had not been engaged in any audit activity $(54,21 \%)$ were spread in very low numbers among the different specialties represented (for example, from two in general medicine and one in surgery to eight in anaesthesia). Only in psychiatry were the numbers not engaged in audit proportionally large, with 19 of the 36 respondents in psychiatry reporting no audit activity.

In terms of the components of care being addressed $47(23 \%)$ of the 207 respondents engaged in audit said that the last audit in which they had participated had been concerned with access to services, 51(25\%) with communication, $158(79 \%)$ with appropriateness of treatment, and $157(78 \%)$ with effectiveness of treatment; therefore several respondents thought that the audit had concerned more than component of care. Standards had been set as part of the audit in only $83(41 \%)$ of audits reported. Respondents were involved in setting standards in $44(29 \%)$ audits, just over half of those audits in which standards had been set.

Answering whether they considered that the last audit they had participated in had helped patient care, $172(86 \%)$ respondents thought that it had. Only in the specialties of psychiatry and pathology did a minority $(40 \%$ and $39 \%$ respectively) agree. In terms of the second part of the questionnaire, about views on audit, an overall mean value was computed as a measure of attitudes to audit (the higher the mean, the more positive the attitude). The mean values were 3.29 for senior registrars and 3.22 for registrars, which were not significantly different, but showed that, overall, these doctors felt somewhat favourably towards audit. There was no significant correlation for either group between the length of time at that grade and positiveness of attitude towards audit.

The mean usefulness of the audit in terms of the doctors' own education was $3 \cdot 2$ (SD $1 \cdot 1$ ), just towards the "useful" end of the 5 point scale. Mean usefulness was not significantly different between registrars and senior registrars. Those specialties which were regarded by respondents as the most useful to them educationally were all small specialties such as renal medicine (4.7); accident and emergency medicine $(4 \cdot 5)$; oncology, plastic surgery, oral surgery, and rehabilitation (all $4 \cdot 0$ ), each of which was represented by only one to three respondents; and elderly medicine (3.9) with six respondents. Because of the small numbers these results clearly represent individual experiences of audit and so cannot be generalised. Audit activity was not considered particularly useful educationally in two large specialties: general medicine $(2 \cdot 7)$ and cardiology $(2 \cdot 8)$, though several smaller specialties showed considerably more negative results.

Those $135(67 \%)$ junior doctors responsible 
for gathering the data in the reported audits found the overall audit activity significantly less useful to them than the other junior doctors (mean usefulness $2.3 v 3.4, t=6 \cdot 1$; $\mathrm{p}<0.001)$. Similarly, the $118(59 \%)$ junior doctors who said they were responsible for collating and reporting the data also perceived the exercise as less useful (mean usefulness $2 \cdot 7$ $v 3 \cdot 2, t=5 \cdot 1 ; \mathrm{p}<0 \cdot 0001)$.

A contents analysis was performed on the replies of 185 respondents who indicated what would make the experience of audit more useful for them. The table shows the 231 items mentioned coded into 12 categories and subcategories. The largest category $(35 \%$ of items) was for better audit methods, especially criticism of the vagueness of audit plans and designs. For example, "Audit is performed badly in a halfhearted fashion to satisfy college requirements, in order to protect consultants or hospitals from losing recognition for training and therefore junior staff" (general surgeon). Other points were stated by those who wished to see the audit loop closed so that change was the outcome of the audit - for example, "Audit would be more useful to me if action were taken on the results. There is not an obvious change in policy despite the audit" (respondent from obstetrics and gynaecology). Twelve per cent of the items were about the amount of time devoted to audit. A few respondents reported having done the work on their own computers and in their own time; others suggested that they should be given dedicated time for audit and others that a financial incentive to do audit would be useful.

Several comments requested audits specially designed for doctors in training. Most were about the short period involved - for example,

Classification of 231 items in replies of 185 respondents on what would make audit more helpful for junior doctors

\begin{tabular}{|c|c|c|}
\hline Category & No & $(\%)$ \\
\hline $\begin{array}{l}\text { Time (for example, so audit isn't an extension } \\
\text { of the working day) }\end{array}$ & 27 & 12 \\
\hline $\begin{array}{l}\text { Cooperation between consults (for example, } \\
\text { less bickering) }\end{array}$ & 4 & 2 \\
\hline $\begin{array}{l}\text { More participation in audit activity } \\
\text { By consultants (including more enthusiasm) } \\
\text { With other departments, professions }\end{array}$ & $20^{25}$ & $9^{11}$ \\
\hline Funding (for example, for long term projects) & 5 & 2 \\
\hline $\begin{array}{l}\text { Selection of topic } \\
\text { More involvement of junior doctors } \\
\text { Too many morbidy audits }\end{array}$ & $\begin{array}{c}21 \\
6\end{array}$ & $6^{9}$ \\
\hline $\begin{array}{l}\text { Better data collection needed } \\
\text { Dedicated staff (that is not junior doctors) } \\
\text { Data from notes is poor }\end{array}$ & $\begin{array}{c}20 \\
14^{20}\end{array}$ & $6^{9}$ \\
\hline More expert help needed (audit, statistics) & 13 & 6 \\
\hline $\begin{array}{l}\text { Better methods needed } \\
\text { General (for example, too much case }\end{array}$ & 82 & 35 \\
\hline $\begin{array}{l}\text { analysis, no operational definitions, } \\
\text { design too vague, no plans for data) }\end{array}$ & 26 & 11 \\
\hline Standard should be set & 10 & 4 \\
\hline $\begin{array}{l}\text { Need more prospective audits } \\
\text { Need long term follow ups, general }\end{array}$ & 11 & 5 \\
\hline & 5 & 2 \\
\hline $\begin{array}{l}\text { Need comparisons with other hospital, } \\
\text { regions, etc }\end{array}$ & 9 & 4 \\
\hline $\begin{array}{l}\text { Must see audit loop is closed, action plans, } \\
\text { change }\end{array}$ & 21 & 9 \\
\hline $\begin{array}{l}\text { Need better or more positive feedbacks to } \\
\text { junior doctors }\end{array}$ & 7 & 3 \\
\hline $\begin{array}{l}\text { More education in audit for junior doctors } \\
\text { and undergraduate students }\end{array}$ & 14 & 6 \\
\hline $\begin{array}{l}\text { More computers and computerisation } \\
\text { (coding, etc) }\end{array}$ & 10 & 4 \\
\hline More help from general management & 3 & 1 \\
\hline
\end{tabular}

"Because of the six month placements, I don't see any results of the project and have to move on to a different job. Starting the project at the beginning of the six months would often give adequate time for it to be completed" (anaesthetist). Other problems for juniors concerned feedback - for example, "Negative feedback to juniors leads to 'economies with the truth;"" "Witch-hunting juniors in mortality meetings should stop;" and "Audit took the form of morbidity meetings where suicides or poor outcomes were discussed. The set up was such that the presenting trainee was grilled and frequently felt threatened and blamed for any identified deficiencies in care. Trainees therefore became increasingly reluctant to bring material for discussion. The meetings would have been more useful if non-threatening, and nonblame apportioning with more constructive comments" (psychiatrist). Finally, there were expressions of a general unhappiness about the attitudes of some consultants - for example, "Consultants don't seem to be the subject of audits" and "The audit meetings tend to deteriorate into 'slanging matches' with one team vindictively telling the other team it shouldn't have done this or that. The atmosphere was such that mistakes tended to be covered up rather than discussed" (pathologist). One respondent asked, "Is audit to educate junior staff? I think not."

\section{Discussion}

Our data need to be interpreted in the light of a low response rate to the questionnaire. This may have been caused by the common problem of incomplete staff lists or by factors within the subjects, such as low morale or apathy. Also many junior doctors not involved in any audit activity may not have responded. As the questionnaire was anonymous we were unable to follow up non-respondents. There is therefore no way of judging the possible differences in attitudes between respondents and non-respondents, though previous studies suggest that non-respondents may be more disaffected. ${ }^{4}$ Possibly therefore our results are overoptimistic in that they are based on only those doctors who felt they knew enough about audit to make sensible replies.

The results indicate that these doctors generally perceived medical audit favourably and that most thought that they were engaged in an activity which was helpful to patients. It is of some concern, however, that a fifth of respondents were engaged in no audit activity, more than a third $(35 \%)$ of whom were in psychiatry. In terms of the types of audits carried out, the components of care were all represented, in particular appropriateness and effectiveness of treatment, though the liberal agreement that the audit had concerned several topics makes us question whether the specific topic had simply been unclear.

Standards had been set in less than half of the audits reported, and only $29 \%$ of respondents had been part of the team which set the standards. This aspect of the audit cycle is regarded as most important 
educationally ${ }^{2}$ in getting doctors to consider what is good care but also in giving more meaning to the rest of the audit cycle and the tasks it entails.

These doctors overall saw their audit activity as somewhat useful, though in only a few small specialties was it rated really positively. It seems clear that these very positive (and also the very negative) expressions came from particular experience of an audit which worked well (or badly) for the individual doctors concerned. The audits which were seen as most useful were clearly not those in which junior doctors collect, analyse, and report the data. Although this is one way that they may progress fully around the audit cycle, the resulting dissatisfaction may come from junior doctors' feelings of general overload. Working with an audit assistant on at least one project should let these doctors gain knowledge of more efficient methods and appreciate simpler ways of extracting and analysing data.

The qualitative data provide us with extra information about how medical audit activity might be made more useful in doctors' postgraduate education. The greatest improvements were required in audit methods and reflected requests for clarity of design and, especially, completion of the audit cycle so that change is actually seen in practice. The ways that audits might be increasingly designed to include trainees in the total audit cycle is a key issue in training, and more explicit guidance on useful methods by the colleges would be helpful. In some provider units trainees and their consultant put forward joint bids for audit money; others encourage small six month audit projects which allow the junior doctor to progress twice around the audit loop. Nevertheless, real problems still remain in designing audits which are relevant to the six or 12 month "work cycle" of junior doctors. When this has been achieved audit will become a truly experiential educational activity which may help empower juniors to improve their contribution to patient care.

Because of the apparently positive attitudes of most of the respondents towards audit generally, timetabling audit needs to be encouraged so that it is not added on to the working days of junior doctors, at least not without an overtime payment from the audit budget. Nevertheless, it is clear that several registrars and senior registrars view audit not as a rewarding educational activity but as a chore or even a threat. This may reflect the attitude of their consultants, but it bodes ill for the respondents' future enthusiasm for audit when they themselves become consultants. It would be sad if audit joined other aspects of training and formed a "cycle of resentment."

Another crucial area is training in audit methods, both at undergraduate and postgraduate levels. Although some lectures are given on the topic to undergraduates, giving them audit projects at that stage would be far more practically useful. It is essential that all doctors in training should be introduced to audit in ways which they find stimulating and useful to themselves and their patients.

The Department of Health has stated that extra resources are required to provide training in medical audit ${ }^{1}$ and that a proportion of the money provided to regional health authorities to finance medical audit is for educational aspects of audit and training in audit techniques. ${ }^{6}$ In this study the low proportion of audits in which standards had been set may indicate that education about audit should be provided for consultants as well as juniors. Certainly, our data imply that some consultants might benefit from courses in designing and completing audits, in the improvements that audit can bring to patient care, and in ways to use audit educationally with junior doctors.

This project was funded by a regional grant for medical audi from Yorkshire Health

1 Department of Health. The quality of medical care. Report of the Standing Medical Advisory Committee for the Secretaries of State for Health and Wales. London: HMSO, 1990.

2 Standing Committee on Postgraduate Medical Education. Medical audit: the educational implications. London: SCOPME, 1989.

3 Firth-Cozens J, Morrison LA. Sources of stress and ways of coping in junior house officers. Stress Medicin 1989;5:121-6.

4 Vernon SW, Roberts RE, Lee ES. Ethnic status and participation in longitudinal health studies. $A m \mathscr{J}$ Epidemiol 1984;119:99-113.

5 Firth-Cozens J. The stresses of medical training. In: Payne RP, Firth-Cozens J, eds. Stress in health professionals. Chichester: Wiley, 1987:3-22.

6 Department of Health. Medical audit in $\mathrm{HCHF}$ - allocation of funds 1991-2. London: HMSO, 1990. (EL(91)32.) 